\title{
New plan from industry to preserve Bt crops
}

This January, the members of an industry coalition consisting of companies that produce Bacillus thuringiensis (Bt) engineered corn seed outlined an industry version of a unified plan to preserve Bt insecticidal toxins and extend the useful lifetime of crop plants that are engineered to produce these insecticides. Monsanto (St. Louis, MO), Novartis Seeds (Greensboro, NC), Pioneer Hi-Bred (Des Moines, IA), and Mycogen-Dow AgroScience (Midland, MI) are following the advice, given in

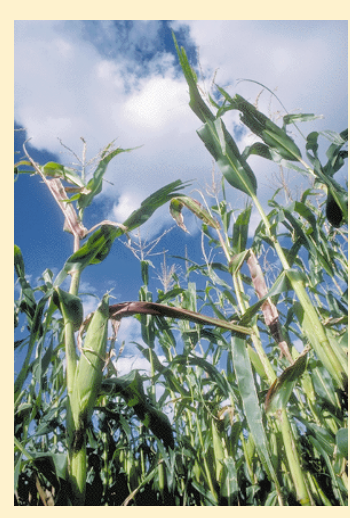

ing crops (Nat. Biotechnol. 15:499, 1997). So far, EPA is not insisting on a refuge setaside, and the industry would prefer to implement a Btpreservation program on a voluntary basis. Although details are being negotiated, the proposed plan calls for farmers who plant Bt-producing corn seed to set aside $20 \%$ of their cropland as refuges in which to plant conventional corn, some of which may be treated with conventional insecticides during the growing season. Because the proposal entails June last year, of the members of a scientific uniform refuge set-asides, it could lead to panel convened by the US Environmental better compliance by growers because what Protection Agency (EPA; Washington, DC) they need to do to meet this Bt-preservawho urged the agency to "require the use of tion strategy is straightforward, according structured refuges" to preserve Bt-produc- to a spokesperson from Monsanto.

\section{Another hiccup at British Biotech}

At the end of 1998, British Biotech (Oxford, UK) terminated a phase III trial of marimastat, its matrix metalloproteinase inhibitor cancer drug, after realizing that the design of the trial would not generate data suitable for regulatory approval. According to a company spokesperson, the end point of the trial一an unusual composite measure involving a combination of CT scans, levels of cancer antigens, and patient "well-being" (as opposed to survival) - would not produce data that the European Medicines Evaluation Agency (EMEA; London) and the US Food and Drug Administration (FDA; Rockville, MD) would accept for approval. However, the company points out this is only 1 of 11 trials; the remaining 10 , which cite survival as an endpoint, will continue as they are. "Three-quarters of a million pounds will be saved" as a result of halting the trial, says the company positively, although $£ 250,000$ had already been spent on recruitment for the trial. The inadequacies of the marimastat trial were spotted during an external assessment of the company's technology following the firing of its head of clinical trials, Andrew Millar, and the resignation of CEO Keith McCullagh last year (Nat. Biotechnol. 16:609).

\section{More merger of markets}

Euro.NM announced at the end of 1998 its intention to merge with the Stockholm bourse and the Copenhagen Exchanges, ending rumors of a merger between Euro.NM and Easdaq (Nat. Biotechnol. 16:1301, 1998). However, accord-

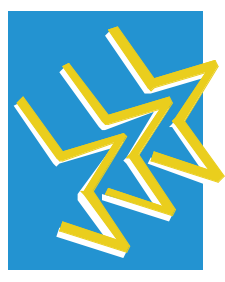

EURO.NM ing to Clive Pedder, director of marketing at Easdaq, the problems that faced the potential Easdaq-Euro.NM merger-namely a lack of clarity regarding how a combined exchange would operate-are also a concern for the proposed new merger. Pedder thinks the concept of a merger between exchanges is valid, but that such ties are worthless unless a single set of rules regulates all the exchanges and they are all linked electronically. Robert Thys, director of marketing at Euro.NM-itself a group of four associated exchanges from Germany, France, The Netherlands, and Belgium — says only that "each exchange will operate within its own framework." Until the hurdle of complete integration can be overcome, says Pedder, "investors will continue to see the [new merged] exchanges as separate local markets, rather than a single pan-European one." 